ORIGINAL ARTICLE

\title{
Influence of years engaged in agriculture and number of pregnancies and deliveries on mortality of inhabitants of the Jinzu River basin area, Japan
}

\author{
E Kobayashi, Y Okubo, Y Suwazono, T Kido, M Nishijo, H Nakagawa, K Nogawa
}

See end of article for authors' affiliations

Correspondence to: Dr E Kobayashi,

Department of

Occupational and

Environmental Medicine,

Graduate School of

Medicine (A2), Chiba

University, 1-8-1 Inohana,

Chuohku, Chiba

260-8670, Japan;

etuko@med.m.chiba-u.ac.jp

Accepted 10 April 2002

Background: The occurrence of itai-itai disease is thought to be affected by such factors as pregnancy, lactation, hormonal disorders, aging, and calcium deficiency.

Aims: To study the influence of years engaged in agriculture and number of pregnancies and deliveries on the mortality of inhabitants of the Jinzu River basin area, which has been an endemic region for itai-itai disease.

Methods: From 6667 participants (3181 men, 3486 women; participation rate 93.4\%) in the 1967 health survey, 3639 subjects (1591 men, 2048 women) whose years engaged in agriculture were established, and 2559 women/2410 women with a known number of pregnancies/deliveries were selected as the target population. These data were confirmed on the basis of self reported replies confirmed afterwards by interview. The survival survey was conducted for 6127 days from 1 August 1967 to 10 May 1984. Subjects were divided according to three water systems: the Jinzu River, non-Jinzu River, and mixed water system; the influence on mortality of the years engaged in agriculture and the number of pregnancies/deliveries was analysed using a Cox's proportional hazards model according to the water systems.

Results: The mean years engaged in agriculture and mean number of pregnancies/deliveries were not different among the three water systems. Cox's hazard ratios of these parameters to mortality were not statistically significant in the any of the water systems.

Conclusions: Neither the years engaged in agriculture nor the number of pregnancies/deliveries influenced mortality in subjects living not only in the non-Jinzu River basin but also in the Jinzu River basin using a Cox's proportional hazards model.

C admium contamination from an upstream mine in the Jinzu River basin of the Toyama Prefecture led to the development of itai-itai disease, representing the most severe stage of chronic Cd intoxication in many of the inhabitants of this region since the second world war. ${ }^{1}$ Most itai-itai disease patients are elderly postmenopausal women presenting with renal and bone damage. The Japanese word "itai" means "ouch" or "painful" in English. The pain results from unusual changes in bone: osteomalacia with osteoporosis. In May 1968 the Japanese Ministry of Health and Welfare concluded that itai-itai disease developed from osteomalacia corresponding with renal dysfunction from chronic $\mathrm{Cd}$ poisoning, and was affected by factors such as pregnancy, lactation, hormonal disorders, aging, calcium deficiency, and others. ${ }^{2}$ In the Jinzu River basin, Nakagawa et al reported a higher mortality and lower life span linked to patients with itai-itai disease and subjects with suspected disease compared to controls. ${ }^{3}$ However, no studies were undertaken to clarify the relation between mortality and factors such as pregnancy, lactation, hormonal disorders, aging, or calcium deficiency in the general population, nor have such studies been undertaken in the other Cd polluted regions of Japan.

We proposed that the occurrence of itai-itai disease could be affected not only by the number of pregnancies/deliveries in women, but also by hard agricultural labour. In this study we investigated the influence of such factors on the mortality of inhabitants of the Jinzu River basin area.

\section{SUBJECTS AND METHODS}

In 1967 and 1968, large scale health examinations were conducted among the entire population aged $\geqslant 30$ years of the
Jinzu River basin, non-Jinzu River basin, and a region receiving a mixed water supply. The non-Jinzu River basin is irrigated by two rivers which are not polluted by $\mathrm{Cd}$. Each water system has been used for field irrigation. Subjects for the present study were selected from the 6667 participants (3181 men, 3486 women; participation rate $93.4 \%$ ) of the 1967 health survey, which was conducted mainly in the heavily polluted region. ${ }^{4}$ Of these, 3639 subjects (1591 men, 2048 women) having worked a known number of years in agriculture, and women having a known number of pregnancies (2559 women) and deliveries (2410 women) were selected as the target population of the present study. These data were confirmed on the basis of self reported replies confirmed afterwards by interview. Figure 1 shows the selection process for the study population. The survival survey was conducted for 6127 days, from 1 August 1967 to 10 May 1984.

The subjects were divided according to three water systems: the Jinzu River, non-Jinzu River, and a mixed water system; the influence on mortality of the years engaged in agriculture and the number of pregnancies/deliveries was analysed using a Cox's proportional hazards model, using subjects' age as of 1 August 1967.

\section{RESULTS}

Table 1 shows the standardised mortality ratios (SMRs) and the number of subjects at the start and end of the observation period, number of deaths during this period, mean number of observed person-days, mean years engaged in agriculture and number of pregnancies/deliveries according to the water system and gender. Among the three water systems there were 


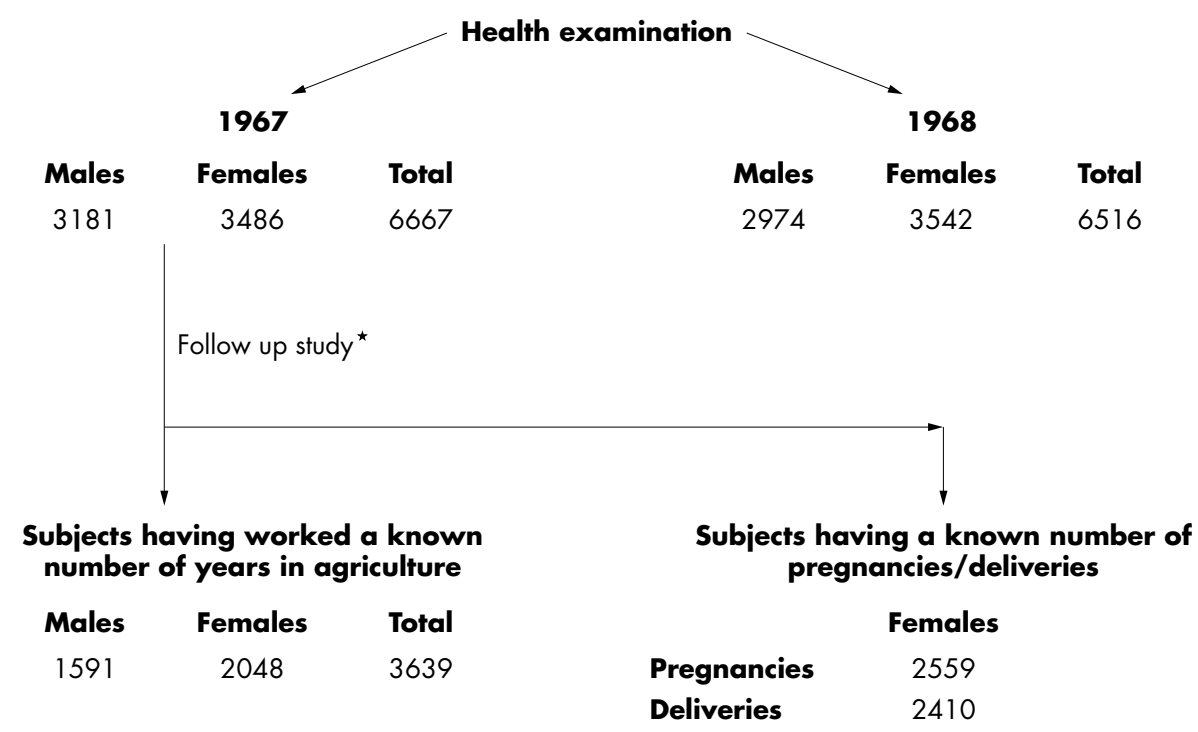

Figure 1 Selection process of the study population. *Follow up study was performed for the subjects who participated in the 1967 health examination.

Table 1 Standardised mortality ratios (SMRs) and inhabitants observed, concerning years engaged in agriculture, number of pregnancies or deliveries, by water system and gender

\begin{tabular}{|c|c|c|c|c|c|c|}
\hline & \multicolumn{2}{|l|}{ SMR } & \multicolumn{2}{|c|}{ Agriculture } & \multirow{2}{*}{$\begin{array}{l}\text { Pregnancy } \\
\text { Females }\end{array}$} & \multirow{2}{*}{$\begin{array}{l}\text { Delivery } \\
\text { Females }\end{array}$} \\
\hline & Males & Females & Males & Females & & \\
\hline The other river & 0.98 & 1.06 & & & & \\
\hline No. examined & & & 430 & 542 & 690 & 651 \\
\hline No. examined completely & & & 422 & 522 & 659 & 619 \\
\hline Mean number of observed person-days & & & 5235 & 5600 & 5491 & 5487 \\
\hline No. deaths & & & 125 & 97 & 136 & 129 \\
\hline Mean of age & & & 51.8 & 48.7 & & \\
\hline Mean years engaged in agriculture $(y)$ & & & 31.3 & 27.4 & & \\
\hline Mean number of pregnancies & & & & & 4.2 & \\
\hline Mean number of deliveries & & & & & & 3.8 \\
\hline Jinzu River + the other & 0.76 & 0.96 & & & & \\
\hline No. examined & & & 164 & 261 & 244 & 220 \\
\hline No. examined completely & & & 164 & 197 & 237 & 214 \\
\hline Mean number of observed person-days & & & 5514 & 5666 & 5605 & 5579 \\
\hline No. deaths & & & 35 & 30 & 41 & 37 \\
\hline Mean of age & & & 50.4 & 50.1 & & \\
\hline Mean years engaged in agriculture $(y)$ & & & 30.4 & 29.6 & & \\
\hline Mean number of pregnancies & & & & & 4.4 & \\
\hline Mean number of deliveries & & & & & & 4.0 \\
\hline Jinzu River & 0.90 & 1.05 & & & & \\
\hline No. examined & & & 997 & 1245 & 1625 & 1539 \\
\hline No. examined completely & & & 995 & 1239 & 1599 & 1515 \\
\hline Mean number of observed person-days & & & 5328 & 5513 & 5501 & 5491 \\
\hline No. deaths & & & 280 & 259 & 336 & 323 \\
\hline Mean of age & & & 51.7 & 49.6 & & \\
\hline Mean years engaged in agriculture $(y)$ & & & 31.8 & 28.3 & & \\
\hline Mean number of pregnancies & & & & & 4.3 & \\
\hline Mean number of deliveries & & & & & & 3.9 \\
\hline
\end{tabular}

no differences in mean years engaged in agriculture or mean number of pregnancies/deliveries.

Using a Cox's proportional hazards model we investigated whether trends in years engaging in agriculture could be correlated to mortality. Table 2 shows the results according to the water system and gender. The Cox's hazard ratio for males living in the mixed water system region was statistically significant, while the hazard ratios of the others were not.

Using the same method we analysed the possible influence on mortality of the number of pregnancies/deliveries in women (table 3). The Cox's hazard ratio of number of pregnancies/deliveries was not statistically significant in any of the studied water systems.

\section{DISCUSSION}

It is well known that exposure to $\mathrm{Cd}$ leads to renal dysfunction, particularly in the renal tubule. ${ }^{5}$ The influence of renal dysfunction on mortality was investigated in Cd polluted areas of Japan. Nakagawa et al and Nishijo et al conducted surveys in the Cd polluted Kakehashi River basin in the Ishikawa 
Table 2 Analysis of length of agriculture, related to mortality, using proportional hazard model of Cox, by water system and sex

\begin{tabular}{|c|c|c|c|c|}
\hline & Regression coefficient & SE & Hazard ratio & $\mathrm{p}$ \\
\hline \multicolumn{5}{|l|}{ Males } \\
\hline \multicolumn{5}{|c|}{ The other river $(n=422)$} \\
\hline Age & $8.70 \times 10^{-2}$ & $1.18 \times 10^{-2}$ & 1.09 & 0.000 \\
\hline Agriculture & $9.58 \times 10^{-3}$ & $8.89 \times 10^{-3}$ & 1.01 & 0.282 \\
\hline \multicolumn{5}{|c|}{ Jinzu River + the other $(n=164)$} \\
\hline Age & $5.56 \times 10^{-2}$ & $2.16 \times 10^{-2}$ & 1.06 & 0.011 \\
\hline Agriculture & $5.11 \times 10^{-2}$ & $1.95 \times 10^{-2}$ & 1.05 & 0.010 \\
\hline \multicolumn{5}{|c|}{ Jinzu River $(n=995)$} \\
\hline Age & $1.13 \times 10^{-1}$ & $8.18 \times 10^{-3}$ & 1.12 & 0.000 \\
\hline Agriculture & $-5.27 \times 10^{-3}$ & $5.79 \times 10^{-3}$ & 1.00 & 0.363 \\
\hline \multicolumn{5}{|l|}{ Females } \\
\hline \multicolumn{5}{|c|}{ The other river $(n=522)$} \\
\hline Age & $1.12 \times 10^{-1}$ & $1.29 \times 10^{-2}$ & 1.12 & 0.000 \\
\hline Agriculture & $-9.46 \times 10^{-3}$ & $1.28 \times 10^{-2}$ & 0.99 & 0.459 \\
\hline \multicolumn{5}{|c|}{ Jinzu River + the other $(n=197)$} \\
\hline Age & $1.53 \times 10^{-1}$ & $3.12 \times 10^{-2}$ & 1.17 & 0.000 \\
\hline Agriculture & $-1.43 \times 10^{-3}$ & $2.58 \times 10^{-2}$ & 1.00 & 0.956 \\
\hline \multicolumn{5}{|c|}{ Jinzu River ( $n=1239$ ) } \\
\hline Age & $1.12 \times 10^{-1}$ & $8.64 \times 10^{-3}$ & 1.12 & 0.000 \\
\hline Agriculture & $2.38 \times 10^{-3}$ & $7.07 \times 10^{-3}$ & 1.00 & 0.737 \\
\hline
\end{tabular}

Table 3 Analysis of number of pregnancies or deliveries, correlated to mortality, using proportional hazard model of Cox, by water system

\begin{tabular}{|c|c|c|c|c|}
\hline & Regression coefficient & SE & Hazard ratio & $\mathrm{p}$ \\
\hline \multicolumn{5}{|l|}{ Pregnancy } \\
\hline \multicolumn{5}{|c|}{ The other river $(n=659)$} \\
\hline Age & $9.81 \times 10^{-2}$ & $6.66 \times 10^{-3}$ & 1.10 & 0.000 \\
\hline No. pregnancies & $-1.89 \times 10^{-2}$ & $3.42 \times 10^{-2}$ & 0.98 & 0.582 \\
\hline \multicolumn{5}{|c|}{ Jinzu River + the other $(n=237)$} \\
\hline Age & $1.50 \times 10^{-1}$ & $1.94 \times 10^{-2}$ & 1.16 & 0.000 \\
\hline No. pregnancies & $8.12 \times 10^{-2}$ & $5.35 \times 10^{-2}$ & 1.09 & 0.131 \\
\hline \multicolumn{5}{|l|}{ Jinzu River ( $n=1599$ ) } \\
\hline Age & $1.09 \times 10^{-1}$ & $5.18 \times 10^{-3}$ & 1.12 & 0.000 \\
\hline No. pregnancies & $2.70 \times 10^{-2}$ & $2.17 \times 10^{-2}$ & 1.03 & 0.213 \\
\hline \multicolumn{5}{|l|}{ Delivery } \\
\hline \multicolumn{5}{|c|}{ The other river $(n=619)$} \\
\hline Age & $1.07 \times 10^{-1}$ & $7.80 \times 10^{-3}$ & 1.11 & 0.000 \\
\hline No. deliveries & $-3.90 \times 10^{-2}$ & $3.65 \times 10^{-2}$ & 0.96 & 0.286 \\
\hline \multicolumn{5}{|c|}{ Jinzu River + the other $(n=214)$} \\
\hline Age & $1.51 \times 10^{-1}$ & $2.02 \times 10^{-2}$ & 1.16 & 0.000 \\
\hline No. deliveries & $6.99 \times 10^{-2}$ & $5.75 \times 10^{-2}$ & 1.07 & 0.225 \\
\hline \multicolumn{5}{|l|}{ Jinzu River ( $n=1515)$} \\
\hline Age & $1.08 \times 10^{-1}$ & $5.37 \times 10^{-3}$ & 1.11 & 0.000 \\
\hline No. deliveries & $3.27 \times 10^{-2}$ & $2.34 \times 10^{-2}$ & 1.03 & 0.163 \\
\hline
\end{tabular}

Prefecture, and Iwata et al performed studies in the Cd polluted Kosaka Town in the Akita Prefecture and Tsushima Island in the Nagasaki Prefecture..$^{6-10}$ They showed that inhabitants with increased urinary excretion of $\beta_{2}$ microglobulin or retinol binding protein showed high SMRs and Cox's hazard ratios. Moreover Nishijo et al showed a dose-response relation between urinary Cd and mortality in a 15 year follow up study of 3119 inhabitants of the Cd polluted Kakehashi River basin. ${ }^{11}$ It was clarified that the life span of inhabitants with Cd induced renal dysfunction is shortened. However, studies investigating the influence of other factors on mortality are few, save for the influence of renal dysfunction. In the Jinzu River basin, an association between Cd concentration in rice and mortality was only investigated by Shigematsu ${ }^{12}{ }^{13}$ and Ishihara and colleagues. ${ }^{14}$ The results obtained from the two studies were conflicting. We have performed studies of the association between mortality and Cd concentration in rice, ${ }^{14}$ total Cd intake, ${ }^{15}{ }^{16}$ and other factors ${ }^{17}{ }^{18}$ in the Cd polluted Jinzu River basin, of which this is one.
Thus far, the most systematic and largest scale health examinations were conducted in 1967 and 1968 around the Jinzu River basin. The target population was composed of inhabitants aged $\geqslant 30$ years of rural communities obtaining water from the Jinzu River water system, another river system, and a mixture of the two. The previously mentioned health examinations conducted in 1967 focused mainly on the inhabitants of the heavily polluted region obtaining water from the Jinzu River water system. ${ }^{4}$ Results of the urinary findings have already been reported with regard to the 1967 findings. ${ }^{4}$ It was shown that in the Jinzu River water system the prevalence of proteinuria, glucosuria, and proteinuria + glucosuria were disproportionately high. ${ }^{4}$ Therefore, in this study, we divided the target population according to the water system to clarify the influence of agricultural labour and number of pregnancies/deliveries on mortality of inhabitants of the Jinzu River basin area. Normally, urinary Cd concentration is used as an index of Cd exposure. Since urinary Cd concentrations were measured by a method in which 10-50 ml 
urine were treated with $\mathrm{HNO}_{3} / \mathrm{H}_{2} \mathrm{SO}_{4}$ and extracted with APDC-MIBK in our laboratory in 1967, we could not measure the Cd concentration in many urine samples.

Shigematsu conducted a 30 year (1948-77) survival survey and investigated the relation between Cd concentrations in unpolished rice and mortality in this region. ${ }^{12}{ }^{13}$ He classified regions into three groups according to $\mathrm{Cd}$ concentrations in unpolished rice, and reported that SMRs for heart disease, hypertension, and cardiovascular disease were significantly lower, and SMR for uraemia was significantly increased in the polluted compared to the non-polluted regions in the Jinzu River basin. Nishijo et al performed a follow up study for 15 years on 2408 inhabitants living in the Kakehashi River basin in Ishikawa Prefecture, ${ }^{7}$ and found that the prognosis of the exposed inhabitants with renal tubular dysfunction was unfavourable, and that the increases in mortality were caused by heart failure and renal disease among the Cd exposed inhabitants. Except for uraemia or renal disease, no specific or common causes of death have been found in either study. Moreover, 83 postmortem examinations were performed on patients with itai-itai disease and subjects with suspected disease, and no specific causes of death were found in the patients. In this study deaths within the target population were investigated via interviews of the families and were confirmed by checking resident cards. As we did not obtain death certificates, the causes of death could not be investigated.

Itai-itai disease developed as a result of $\mathrm{Cd}$ contamination from an upstream mine in the Jinzu River basin; 180 of 183 patients with itai-itai disease and 97 of 114 subjects with suspected disease were women (on 28 December 1999). Alternatively, the Jinzu River basin is the best granary of the Toyama Prefecture, and most, if not all of its inhabitants were engaged in hard agricultural labour until roughly 1980. After that time most farmers have used agricultural machines for cultivation of rice in the area. It would be of interest to consider whether factors contributing to development of itai-itai disease might have an impact on the mortality of the general population. Studies investigating whether $\mathrm{Cd}$ induced renal injury worsens prognosis of life have been conducted.$^{6-11}$ However, until this report there have been no studies undertaken to clarify the relation between other factors such as pregnancy, lactation, hormonal disorders, aging, and calcium deficiency, and mortality. Using a Cox's proportional hazards model we determined that the years engaged in agricultural labour and the number of pregnancies/deliveries had no discernible influence on mortality in subjects living not only outside of the Jinzu River basin but also in the Jinzu River basin. Although the hazard ratio of the years engaged in agricultural labour for males living in the mixed water system region was statistically significant, the hazard ratios of the others were not. We therefore concluded that the years engaged in agricultural labour had no clear infinfluence on mortality. As mentioned above, the Japanese Ministry of Health and Welfare concluded that itai-itai disease developed from chronic $\mathrm{Cd}$ poisoning and occurence of the disease was affected by factors such as pregnancy, lactation, calcium deficiency, and others. ${ }^{2}$ On the other hand, it was reported that patients with itai-itai disease have a higher mortality and lower life span compared with controls. In this study the years engaged in agricultural labour and the number of pregnancies/deliveries had no discernible influence on mortality. Applying these results to the mortality of itai-itai disease patients, it was thought that high mortality of the patients was mainly caused by effects of $\mathrm{Cd}$ poisoning.
Specifically, our results agreed in part with the conclusion of Japanese Ministry of Health and Welfare in that itai-itai disease developed from chronic Cd poisoning. However, we could not estimate from our investigation the degree of influence of facters other than Cd exposure on occurence of itai-itai disease. The previous epidemiological investigations reported that factors such as years engaged in agriculture, number of pregnancies/deliveries, nutritional, and economical conditions were not different between homes with and without itai-itai disease. $^{19}$

\section{Authors' affiliations}

E Kobayashi, Y Okubo, Y Suwazono, K Nogawa, Department of Occupational and Environmental Medicine, Graduate School of

Medicine, Chiba University, Japan

T Kido, Department of Community Health Nursing, Kanazawa University School of Health Sciences, Japan

M Nishijo, H Nakagawa, Department of Public Health, Kanazawa Medical University, Japan

\section{REFERENCES}

1 Nogawa K, Kido T. Itai-itai disease and health effects of cadmium. In: Chang LW, ed. Toxicology of metals. New York: CRC, 1996:353-69.

2 Ministry of Health and Welfare. Opinion of the Welfare Ministry with regard to "itai-itai" disease in Toyama Prefecture, May 8, 1968a [in Japanese]. Environmental Agency, 1972:3.

3 Nakagawa $\mathbf{H}$, Tabata $M$, Morikawa Y, et al. High mortality and shortened life-span in patients with itai-itai disease and subjects with suspected disease. Arch Environ Health 1990;45:283-7.

4 Fukushima $M$, Ishizaki A, Nogawa K, et al. Epidemiological studies on renal failure of inhabitants in "itai-itai" disease endemic district (Part 1) Some urinary findings of inhabitants living in and around the endemic district of the Jinzu River basin [in Japanese]. Japanese Journal of Public Health 1974:21:65-73.

5 Nogawa K, Kobayash E, Honda R, et al. Renal dysfunctions of inhabitants in a cadmium-polluted area. Environ Res 1980;23:13-23.

6 Nakagawa H, Nishijo M, Morikawa $Y$, et al. Urinary $\beta_{2}$-microglobulin concentration and mortality in a cadmium-polluted area. Arch Environ Health 1993:48:428-35.

7 Nishijo $M$, Nakagawa H, Morikawa $Y$, et al. Mortality of inhabitants in an area polluted by cadmium: 15 year follow up. Occup Environ Med 1995;52:181-4

8 Iwata K, Saito H, Moriyama M, et al. Association between renal tubula dysfunction and mortality among residents in a cadmium-polluted area Nagasaki, Japan. Tohoku J Exp Med 1991:164:93-102.

9 Iwata K, Saito H, Nakano A. Association between cadmium-induced renal dysfunction and mortality: further evidence. Tohoku J Exp Med 1991; 164:319-30.

10 Iwata K, Saito H, Moriyama M, et al. Follow up study of renal tubular dysfunction and mortality in residents of an area polluted with cadmium. BrJ Ind Med 1992;49:736-7.

11 Nishijo M, Nakagawa H, Morikawa Y, et al. Relationship between urinary cadmium and mortality among inhabitants living in a cadmium polluted area in Japan. Toxicol Lett 1999;108:321-7.

12 Shigematsu I. An epidemiological study on the cause of death among the inhabitants in cadmium polluted areas [in Japanese]. Kankyo Hoken Report 1980;46: 1-110.

13 Shigematsu I. An epidemiological study on the cause of death among the inhabitants in cadmium polluted areas (Supplement) [in Japanese]. Kankyo Hoken Report 1982;48:118-38.

14 Ishihara T, Kobayashi E, Okubo Y, et al. Association between cadmium concentration in rice and mortality in the Jinzu River basin, Japan. Toxicology $2001 ; 163: 23-8$.

15 Kobayashi E, Okubo Y, Suwazono Y, et al. Association between total cadmium intake calculated from the cadmium concentration in household rice and mortality among inhabitants of the cadmium-polluted Jinzu River basin of Japan. Toxicol Lett 2002;129:85-91.

16 Matsuda K, Kobayashi E, Okubo K, et al. Association between total cadmium intake and mortality among residents in the cadmium-polluted Jinzu river basin, Japan. Arch Environ Health. In press.

17 Matsuda T, Kobayashi E, Okubo Y, et al. Association between renal dysfunction and mortality among inhabitants in the region around the Jinzu River basin polluted by cadmium. Environ Res 2002;88:156-63.

18 Kobayashi E, Okubo Y, Suwazono Y, et al. Association between urinary calcium excretion level and mortality in inhabitants of the Jinzu River basin area of Japan. Biol Trace Elem Res. In press.

19 Study group for itai-itai disease. Report of "itai-itai disease" [in Japanese]. 1967:39-43. 